\title{
Impact of SLC20A1 on the Wnt/ $\beta$-catenin signaling pathway in somatotroph adenomas
}

\author{
JIANHUA LI ${ }^{1,2}$, WEI DONG ${ }^{3}$, ZHENYE LI $^{4}$, HONGYUN WANG $^{1}$, HUA GAO $^{1}$ and YAZHUO ZHANG ${ }^{1,4}$ \\ ${ }^{1}$ Key Laboratory of Central Nervous System Injury Research, Beijing Neurosurgical Institute, Capital Medical University, \\ Beijing 100070; ${ }^{2}$ Department of Neurosurgery, Binzhou People's Hospital, Binzhou, Shandong 256610; \\ ${ }^{3}$ Department of Neurosurgery, Tangshan People's Hospital, Tangshan, Hebei 063001; \\ ${ }^{4}$ Beijing Tiantan Hospital, Capital Medical University, Beijing 100070, P.R. China
}

Received February 5, 2019; Accepted July 12, 2019

DOI: $10.3892 / \mathrm{mmr} .2019 .10555$

\begin{abstract}
Studies have revealed that genetic and functional aberrations of oncogenes, tumor-suppressor genes, signaling pathways and receptors are among the most prominent events in pituitary tumorigenesis, and a potent biomarker would be helpful for early diagnosis, subsequent treatment and disease control. The present study investigated the expression signatures of solute carrier family 20 member 1 , also known as phosphate transporter 1 (SLC20A1) and the Wnt/ $\beta$-catenin signaling pathway in 52 patients with somatotroph adenomas. According to immunohistochemistry analysis, the $\mathrm{H}$-score of SLC20A1 was $222.6 \pm 15.2$ in invasive tumor samples and $144.5 \pm 30.4$ in non-invasive tumor samples $(\mathrm{P}<0.01)$, while the $\mathrm{H}$-scores of $\beta$-catenin were $210.1 \pm 21.4$ and $134.9 \pm 32.7$, respectively $(\mathrm{P}<0.05)$. The $\mathrm{H}$-scores of Wnt inhibitory factor 1 (Wif1) exhibited the opposite trend, with scores of $134.5 \pm 22.7$ and $253.6 \pm 14.8$, respectively $(\mathrm{P}<0.01)$. The H-scores of SLC20A1 were negatively associated with those of Wif1 in somatotroph adenomas (correlation coefficient $r=-0.367$ ). The mean progression-free survival in the low SLC20A1 group was longer than that in the group with high SLC20A1 H-scores $(\mathrm{P}=0.024)$. Reverse transcription-quantitative PCR (RT-qPCR) and western blotting confirmed the interference efficiency of the segments short hairpin (Sh)-B-SLC20A1 and Sh-C-SLC20A1. Cell proliferation experiments revealed that the cell viability of the Sh-B-SLC20A1 group was $76.3 \pm 4.5,65.7 \pm 3.7$ and $53.1 \pm 3.2 \%$ of that of control GH3 cells after 24,48 and $72 \mathrm{~h}$ of transfection, respectively, while the cell viability of the Sh-C-SLC20A1 group
\end{abstract}

Correspondence to: Dr Hua Gao or Dr Yazhuo Zhang, Key Laboratory of Central Nervous System Injury Research, Beijing Neurosurgical Institute, Capital Medical University, 119 Southwest 4th Ring, Beijing 100070, P.R. China

E-mail: huagao@aliyun.com

E-mail: zyz2004520@yeah.net

Key words: somatotroph adenomas, solute carrier family 20 (phosphate transporter), member $1, \mathrm{Wnt} / \beta$-catenin signaling pathway, Wnt inhibitory factor 1 , invasion was $86.4 \pm 5.7,75.6 \pm 4.4$ and $67.5 \pm 3.8 \%$, respectively $(\mathrm{P}<0.05)$. ELISA analysis demonstrated the growth hormone $(\mathrm{GH})$ levels in the Sh-B-SLC20A1 and Sh-C-SLC20A1 groups to be $34.7 \pm 10.4$ and $54.6 \pm 14.4 \%$, respectively, of that of control GH3 cells $(\mathrm{P}<0.05)$. The transmembrane invasion assay revealed that knocking down SLC20A1 significantly suppressed cell invasion in the Sh-B-SLC20A1 and Sh-C-SLC20A1 groups. RT-qPCR and western blotting demonstrated that Sh-B-SLC20A1 and Sh-C-SLC20A1 evidently increased the levels of Wif1 and secreted frizzled-related protein 4 . The present data suggested that SLC20A1 levels are positively associated with tumor size, invasive behavior and tumor recurrence in somatotroph adenomas. Furthermore, SLC20A1 may be associated with the activation of the $\mathrm{Wnt} / \beta$-catenin signaling pathway.

\section{Introduction}

Somatotroph adenomas cause disfiguring growths and medical complications, including cardiovascular and pulmonary complications, and increased mortality rates due to malignancy (1). Acromegaly is mainly caused by somatotroph adenomas that secrete excess growth hormone $(\mathrm{GH})$ and insulin-like growth factor 1 (IGF-1) (2). Somatotroph adenomas are initially treated surgically, followed by radiation and/or medication, if necessary (3). Large tumor sizes and high post-operative IGF-1 levels are predictors for incomplete remission and uncontrolled disease (4). In a complex multistep process, genetic and epigenetic factors, hormonal stimulation, growth factors and their receptors contribute to tumorigenesis and the development of somatotroph adenomas. To date, no high-frequency somatic genetic alterations have been identified in somatotroph adenomas, and the somatic landscape shows $\mathrm{Ca}^{+2}$ and the ATP signaling pathways to be involved in pituitary tumorigenesis (5). However, there is a lack of clinical evidence of phenotype-genotype correlations between the $\alpha$ subunit of stimulatory G-protein (GNAS) in patients with mutated and non-mutated somatotroph adenomas (6).

Inorganic phosphate $(\mathrm{Pi})$ enters the cells via $\mathrm{Na} / \mathrm{Pi}$ cotransporters, which comprise solute carrier (SLC)20 and SLC34 in mammals (7). The SLC20 family consists of two members, namely SLC20A1 [alsoknownas phosphate transporter 1(PiT-1)] and SLC20A2 (PiT2). SLC20A1 encodes sodium-dependent 
phosphate transporter 1 , whose gene is located on chromosome 2q11-14, a log 10 odds peak score region (8). Overexpression of SLC20A1 increases cell proliferation and colony formation in murine fibroblastic NIH3T3 and pre-osteoblastic MC3T3-E1 cells. Furthermore, non-proliferating cells exhibit the lowest SLC20A1 mRNA levels in these cell lines (9). Overexpression of SLC20A1 leads to faster adhesion and spreading compared with control NIH3T3 cells (10). High SLC20A1 expression was associated with worse survival in 401 patients with estrogen receptor-positive breast tumors compared with low SLC20A1 expression (10-year survival rates, 17.16 vs. 68.45\%) (11). The epidermal growth factor receptor inhibitor gefitinib exhibits strong inhibition of cell proliferation in glioblastoma cell lines by regulating SLC20A1 expression (12). In addition, SLC20A1 modulates erythroid maturation by modulating the activity of erythroid Kruppel-like factor in vivo and in vitro (7).

The Wnt signaling pathway has been implicated in the processes of tissue differentiation, proliferation, apoptosis and tumorigenesis (12). The levels of Wnt inhibitory factor 1 (Wif1) and secreted frizzled-related protein 4 (sFRP4) are lower in invasive nonfunctional pituitary adenomas (NFPAs) than in noninvasive NFPAs (13). The present study investigated the expression signatures of SLC20A1 and the Wnt/ $\beta$-catenin signaling pathway in 52 patients with somatotroph adenomas. Furthermore, it explored the possibility that SLC20A1 could be targeted by chemotherapeutic agents or used as a molecular marker for the diagnosis of patients with cancer via RNA interference (RNAi) technology in the GH3 cell line.

\section{Materials and methods}

Patients and tissue specimens. The present study retrospectively reviewed 52 patients (mean age, 40.3 years; range 16-62 years) with somatotroph adenomas at Beijing Tiantan Hospital affiliated to Capital Medical University, between July 2012 and December 2016. The diagnosis of somatotroph adenoma was based on clinical symptoms and histopathological features, per the 2017 World Health Organization Classification (14). All patients were diagnosed with sporadic somatotroph adenomas. The inclusion criteria for recruitment of patients were as follows: i) Serum $\mathrm{GH}>1 \mathrm{ng} / \mathrm{ml}$ and IGF-1 above normal (115-307 ng/ml), or $\mathrm{GH}>2 \mathrm{ng} / \mathrm{ml}$; ii) magnetic resonance imaging confirmed the existence of the saddle area; iii) acromegaly or facial changes; and iv) transmission electron microscopy revealed large secretory granules (400-600 nm). Patients presenting familial pituitary adenoma were excluded from the present study. In addition, three normal pituitary glands were obtained from a donation program at Tianjin First Central Hospital in China (two male and one female patients; age, 21-45). None of the donors had a history of pituitary disease. Progression-free survival (PFS) was defined as the interval between the date of surgery and the date of tumor recurrence or tumor regrowth. The protocols were approved by the Internal Review Board of Beijing Tiantan Hospital affiliated to Capital Medical University and the study was conducted according to the principles of the Declaration of Helsinki (no. KY-2013-02). Informed consent was obtained from all patients.

Immunohistochemistry (IHC). Tissue microarray construction and the IHC protocol were performed according to a previously described method (15). The following primary antibodies were used: Anti-SLC20A1 (cat. no. ab237527; 1:1,000; Abcam), anti- $\beta$-catenin (cat. no. ab32572; 1:2,000; Abcam), anti-Wif1 (cat.no. ab155101; 1:500; Abcam) and anti-Ki 67 (cat. no. ACK02; 1:1,000; Leica Microsystems, Inc.). A secondary antibody (cat. no. sc-2040; 1:5,000; Santa Cruz Biotechnology, Inc.) was used in combination with the Bond Polymer Refine Detection system (cat. no. DS9800; Leica Microsystems, Inc.). Staining intensity was stratified on a scale of 0-3 as follows: 0 , no staining; 1, weak staining; 2 , moderate staining; and 3, strong staining. The $\mathrm{H}$-score was obtained by multiplying the staining intensity by a constant to adjust the mean to the strongest staining, to produce a score in the range of 0-300. Specifically, $\mathrm{H}$-score $=$ scale $\mathrm{x}$ percentage of strong staining $(0-100 \%)$. $\mathrm{H}$-score $=1.0$ indicated a weak percentage; 2.0 indicated a moderate percentage; and 3.0 indicated a strong percentage.

Cell culture, proliferation and migration. GH3 cells were purchased from the American Type Culture Collection (ATCC) and were cultured in F12K (ATCC) supplemented with $2.5 \%$ fetal bovine serum (Gibco; Thermo Fisher Scientific, Inc.) and $15 \%$ horse serum (Gibco; Thermo Fisher Scientific, Inc.) under $37^{\circ} \mathrm{C}$ and $5 \% \mathrm{CO}_{2}$.

The GH3 cells were plated onto 96-well dishes with $1 \times 10^{4}$ cells and $100 \mu \mathrm{l}$ medium in each well, and incubated overnight. SLC20A1 gene silencing in the GH3 cells was established by transfection of short hairpin RNA $(1 \mu \mathrm{g}$ for $1 \times 10^{6}$ cells; OriGene Technologies, Inc.) or non-targeting control shRNA (scramble) for $72 \mathrm{~h}$ using $5 \mu \mathrm{l}$ Opti-MEM (Gibco; Thermo Fisher Scientific, Inc.) and $0.3 \mu 1$ Lipofectamine ${ }^{\circledR} 3000$ (Invitrogen; Thermo Fisher Scientific, Inc.), according to the manufacturer's instructions. The sequences of the pGFP-C-shLenti plasmid were: Scramble, TTCTCCGAACGTGTCACGT; A, CACCGAAGTATGACA ATCTGTGGATGCTC; B, GCAATGCTGTGTCTGACC TTCACTCAGAG; C, ATAGGAATCCTGTGTCTGAGG TAGTATGT; and D, GCTTCTGCTCCACCGAAGTATGAC AATCT. Then, $20 \mu \mathrm{l}$ MTS solution was added to each well and further incubated for $4 \mathrm{~h}$. The absorbance at $490 \mathrm{~nm}$ of each well was measured using an ELISA plate reader (Thermo Fisher Scientific, Inc.).

Cell migration and invasion were measured using fibronectin- and Matrigel-coated polycarbonate filters, respectively, and modified transwell chambers (Corning Inc.). In total, $5 \times 10^{4} \mathrm{GH} 3$ cells in $200 \mu \mathrm{F} 12 \mathrm{~K}$ medium were added into the upper chambers and $600 \mu \mathrm{l}$ medium $[\mathrm{F} 12 \mathrm{~K}+2.5 \% \mathrm{FBS}$ (cat. no. 10099-141; Gibco; Thermo Fisher Scientific, Inc.)+ 5\% horse serum (cat. no. sh30074; HyClone; GE Healthcare Life Sciences] was added into lower chamber. After $24 \mathrm{~h}$, migrating cells that adhered to the lower membrane were fixed in $4 \%$ paraformaldehyde (for $30 \mathrm{~min}$ at $4^{\circ} \mathrm{C}$ ) and stained using hematoxylin (OriGene Technologies, Inc.) for $5 \mathrm{~min}$ at room temperature. The average number of migrated cells was quantified in five randomly selected fields of view under a fluorescence microscope (Zeiss $\mathrm{GmbH}$; magnification, x100) Experiments were performed in triplicate.

ELISA. GH level was detected using an ELISA kit (cat. no. 710685; Shanghai Enzyme-linked Biotechnology Co., Ltd.) according to the manufacturer's protocol. The absorbance 
Table I. Primers used in reverse transcription-quantitative PCR.

\begin{tabular}{lcc}
\hline Gene & Forward primer $\left(5^{\prime}-3^{\prime}\right)$ & Reverse primer $\left(5^{\prime}-3^{\prime}\right)$ \\
\hline SLC20A1 & GCTTTATGGTGGTGTTGGCA & GTGTTGTGCTGATGGGAAGG \\
E-CAD & ACTTTGGTGTGGGTCAGGAA & CACATGCTCAGCGTCTTCTC \\
N-CAD & AGAACAGGGTGGACGTCATT & ACCACTGTGACTAGCCCATC \\
MMP-2 & TGCAACCACAACCAACTACG & TAGAGCTCCTGGATCCCCTT \\
MMP-9 & TGGGCAAGCAGTACTCTACC & GTCTTCATGCAGAGGGGAGT \\
Snail & CGAGCAGAGTTGTCTACCGA & CTGCTGGAAGGTGAACTCCA \\
Vimentin & ACTAATGAGTCCCTGGAGCG & AGGTGGCGATCTCAATGTCA \\
VEGF & CACCAAAGCCAGCACATAGG & TTTAACTCAAGCTGCCTCGC \\
GAPDH & AGTCTACTGGCGTCTTCACC & CCACGATGCCAAAGTTGTCA \\
\hline
\end{tabular}

SLC20A1, solute carrier family 20 member 1; E-CAD, E-cadherin; N-CAD, N-cadherin; MMP, matrix metalloproteinase; VEGF, vascular endothelial growth factor.

at $450 \mathrm{~nm}$ in each well was measured using an ELISA plate reader (M200 Pro; Tecan Group, Ltd.).

Reverse transcription-quantitative PCR (RT-qPCR) analysis. Total RNA was extracted from 24 frozen pituitary adenoma samples $(\sim 10 \mathrm{mg})$ using the RNeasy ${ }^{\circledR}$ Mini Kit (Qiagen $\mathrm{GmbH})$. Purified total RNA (1 $\mu \mathrm{g})$ was reverse transcribed into complementary DNA (cDNA) using a Revert Aid First-Strand cDNA Synthesis kit (Thermo Fisher Scientific, Inc.), based on the manufacturer's protocol $\left(25^{\circ} \mathrm{C}\right.$ for $10 \mathrm{~min}, 37^{\circ} \mathrm{C}$ for $2 \mathrm{~h}, 95^{\circ} \mathrm{C}$ for $5 \mathrm{~min}$ ). The primer details are presented in Table I. GAPDH was used as an endogenous control for normalizing the levels of target genes. RT-qPCR was performed in an ABI 7500 Fast Real-Time PCR System (Applied Biosystems; Thermo Fisher Scientific, Inc.) using Platinum ${ }^{\circledR}$ SYBR ${ }^{\circledR}$ Green qPCR SuperMix-UDG (Invitrogen; Thermo Fisher Scientific, Inc.). The comparative quantification cycle $(\mathrm{Cq})$ method was used to calculate the fold-change in differential expression of each gene ( $2^{-\Delta \Delta \mathrm{Cq}}$ method) (16) the thermocycling conditions were the following: Initial denaturation at $95^{\circ} \mathrm{C}$ for 15 followed by 40 cycles of $94^{\circ} \mathrm{C}$ for $15 \mathrm{sec}, 55^{\circ} \mathrm{C}$ for $30 \mathrm{sec}$ and $74^{\circ} \mathrm{C}$ for $34 \mathrm{sec}$.

SDS-PAGE and western blot analyses. A total of $10 \mathrm{mg}$ specimen was lysed to extract total protein in TNE buffer $(50 \mathrm{mM}$ Tris- $\mathrm{HCl}$, pH 7.4, $150 \mathrm{mM} \mathrm{NaCl}$ and $1 \mathrm{mM}$ EDTA; Sigma-Aldrich; Merck KGaA) containing 1\% Nonidet P-40 (Calbiochem; Merck $\mathrm{KGaA}$ ) with protease and phosphatase inhibitor cocktails (Roche Applied Science). The total protein extracted from somatotroph adenomas or normal pituitary glands was centrifuged at $12,000 \mathrm{x} \mathrm{g}$ for $30 \mathrm{~min}$ at $4^{\circ} \mathrm{C}$, and the protein concentration was determined using a bicinchoninic acid protein assay kit (Pierce; Thermo Fisher Scientific, Inc.). For western blot analysis, $40 \mu \mathrm{g}$ protein per lane was separated electrophoretically using 4-12\% Bis-Tris SDS-PAGE gels and blotted onto polyvinylidene fluoride membranes. Each membrane was blocked for $1 \mathrm{~h}$ with $5 \%$ milk in TBS at room temperature, incubated with antibodies against SLC20A1 (cat. no. ab237527, 1:2,000; Abcam), Wif1 (cat. no. ab155101, 1:1,000; Abcam), $\beta$-catenin (cat. no. ab32527, 1:5,000; Abcam), sFRP4 (cat. no. ab154167, 1:2,000; Abcam) and GAPDH (cat. no. G5262, 1:8,000; Sigma-Aldrich; Merck
$\mathrm{KGaA}$ ) at $4^{\circ} \mathrm{C}$ overnight, and then incubated $1 \mathrm{~h}$ with horseradish peroxidase-tagged secondary antibodies (cat. no. sc-2363, 1:5,000; Santa Cruz Biotechnology, Inc.) at room temperature. Finally, the membranes were visualized by enhanced chemiluminescence (cat. no. sc2048, Santa Cruz Biotechnology, Inc.) using a Versadoc XL imaging system (Amersham Imager 600; GE Healthcare Life Sciences), and densitometry was performed using the ImageQuant TL software (version 7.0; GE Healthcare Life Sciences). GAPDH levels were analyzed as a loading control.

Statistical analysis. The $\chi^{2}$ exact test was used to determine the significance of clinicopathological characteristics and variables. Pearson's correlation coefficient was used to analyze the correlation between $\beta$-catenin/Wif1 expression and SLC20A1 score. Student's t-test was applied to examine the differential expression of SLC20A1, $\beta$-catenin, Ki67 and Wif1 in patient samples. Data are presented as the mean \pm SD. One-way ANOVA was used in cell growth, $\mathrm{GH}$ release and migration of GH3 cells experiments. All P-values were two sided and $\mathrm{P}<0.05$ was considered to indicate a statistically significant difference. All experiments were repeated three times. Analyses were performed using SPSS (vesion 19.0; IBM Corp.).

\section{Results}

Clinicopathological features. There were 28 males and 24 females in the present study (Table SI) with a mean age of 40.3 years (age range, 17-62 years). The median tumor volume was $6.25 \mathrm{~cm}^{3}$ (range, 2.24-18.7 $\mathrm{cm}^{3}$ ). The average level of $\mathrm{GH}$ was $22.83 \pm 7.31 \mathrm{ng} / \mathrm{ml}$, and ranged from 7.9 to $76.2 \mathrm{ng} / \mathrm{ml}$. The number of total resections was $31 / 52(59.6 \%)$, while the number of partial resections was $21 / 52(40.4 \%)$. The number of recurrent cases was 11/52 (21.2\%). Tissues from 52 patients were stained with standard hematoxylin and eosin staining, and IHC was performed with antibodies against SLC20A1, $\beta$-catenin, sFRP4, Ki67 and Wif1. According to the Knosp classification, the 52 patients were classified into an invasive group (15 patients) and a non-invasive group (37 patients). The patients in the invasive group had a greater degree of headache and visual deficits than the patients in the non-invasive group. The preoperative serum GH level was $36.7 \pm 11.9 \mathrm{ng} / \mathrm{ml}$ 
in the invasive group and $17.2 \pm 6.3 \mathrm{ng} / \mathrm{ml}$ in the non-invasive group $(\mathrm{P}<0.05)$. Follow-up data revealed that total resection was carried out in 5/15 (33.3\%) cases in the invasive group and $26 / 37(70.3 \%)$ cases in the non-invasive group $\left(\chi^{2}=4.611\right.$, $\mathrm{P}=0.032)$. Furthermore, recurrence in the invasive group occurred in $6 / 15(40 \%)$ cases and in $5 / 37(13.5 \%)$ cases in the non-invasive group $\left(\chi^{2}=4.489, \mathrm{P}=0.034\right)$ (Table II).

SLC20A1, Wif1, $\beta$-catenin and Ki67 expression signatures in 52 somatotroph adenomas. IHC was used to evaluate the levels of SLC20A1, Wif1, $\beta$-catenin and Ki67 in the 52 somatotroph adenoma samples (Fig. 1A). The H-score of SLC20A1 was $222.6 \pm 15.2$ in the invasive group and $144.5 \pm 30.4$ in the non-invasive group $(\mathrm{P}<0.01)$, while the $\mathrm{H}$-scores of $\beta$-catenin were $210.1 \pm 21.4$ and $134.9 \pm 32.7$ in these two groups, respectively $(\mathrm{P}<0.05)$. The $\mathrm{H}$-scores of Wif1 presented the opposite trend compared with $\beta$-catenin or SLC20A1, with values of $134.5 \pm 22.7$ and $253.6 \pm 14.8$ in the invasive and non-invasive groups, respectively $(\mathrm{P}<0.01)$. The Ki67 index was $6.3 \pm 2.2$ in the invasive group and $1.9 \pm 1.3$ in the non-invasive group. Western blotting also confirmed the same tendency, as depicted in Fig. 1B. In the present study, a high-level case was defined as having a $\mathrm{H}$-score higher than the median value.

According to the H-score median of SLC20A1, Wif1 and $\beta$-catenin, 52 samples were divided into high and low $\mathrm{H}$-score groups. The tumor volume in patients with high SLC20A1 H-scores (high SLC20A1 group) was 8.34 \pm 2.64 and $4.16 \pm 2.39 \mathrm{~cm}^{3}$ in patients with low SLC20A1 H-scores (low SLC20A1 group) $(\mathrm{P}<0.05)$, and the rate of tumor recurrence was $8 / 26(30.8 \%)$ compared with $3 / 26(11.5 \%)$ in these two groups, respectively. Patients with high Wif1 H-scores (high Wif1 group) had less tumor volume $\left(3.14 \pm 2.35\right.$ vs. $\left.9.36 \pm 3.64 \mathrm{~cm}^{3}\right)$ than those with low Wif1 H-scores (low Wif1 group) $(\mathrm{P}<0.05)$ and lower recurrence rates compared with patients in the low Wif1 group, data not shown $\left(2 / 26\right.$ vs. $\left.9 / 26, \chi^{2}=5.65, \mathrm{P}=0.017\right)$. The H-scores of SLC20A1 were negatively associated with the $\mathrm{H}$-scores of $\beta$-catenin in somatotroph adenomas, with a correlation coefficient of 0.366 (Fig. 2A). The correlation coefficient was -0.424 between Wif1 and SLC20A1 (Fig. 2B). PFS associated with low SLC20A1 H-scores was longer than that associated with high SLC20A1 H-scores ( $\mathrm{P}=0.033$, Fig. 3A), while the PFS in the high Wif1 group was longer than that in the low Wif1 group $(\mathrm{P}=0.043)$, as shown in Fig. 3B.

Effects of RNAi-SLC20A1 on cell growth, GH release and migration of GH3 cells. The efficiency of four shRNA segments (Sh-A/B/C/D-SLC20A1) was measured in GH3 cells. RT-qPCR demonstrated that the relative percentages of SLC20A1 mRNAs were $32.3 \pm 10.4,8.2 \pm 5.7,17.7 \pm 8.4$ and $64.9 \pm 22.4 \%$, respectively, after $72 \mathrm{~h}$ of transfection (Fig. $4 \mathrm{~A}$ ) Western blotting also confirmed that the interference efficiency of segment Sh-B was $83.4 \%$ and that of Sh-C was $76.4 \%$ compared with the SLC20A1 protein levels in GH3 cells after $72 \mathrm{~h}$ of transfection (Fig. 4B). Cell proliferation experiments revealed that the cell viability of the Sh-B group was $76.3 \pm 4.5$, $65.7 \pm 3.7$ and $53.1 \pm 3.2 \%$ of control $\mathrm{GH} 3$ cells after 24,48 and $72 \mathrm{~h}$ of transfection, respectively, and that of the Sh-C group was $86.4 \pm 5.7,75.6 \pm 4.4$ and $67.5 \pm 3.8 \%$ of the control group, respectively, after the same time $(\mathrm{P}<0.05$; Fig. 5A). ELISA was used to measure the effect of SLC20A1 on GH secretion
Table II. Univariate analyses of clinicopathological correlates in 52 patients with somatotroph adenomas.

\begin{tabular}{|c|c|c|c|c|}
\hline \multirow[b]{2}{*}{ Variable } & \multicolumn{2}{|c|}{ Invasiveness } & \multicolumn{2}{|c|}{$\begin{array}{c}\text { Univariate } \\
\text { analysis }\end{array}$} \\
\hline & Yes $(n=15)$ & No $(n=37)$ & $\chi^{2}$ & P-value \\
\hline Age, years & & & 2.342 & 0.126 \\
\hline$\leq 40.3$ & 10 & 16 & & \\
\hline$>40.3$ & 5 & 21 & & \\
\hline Sex & & & 0.843 & 0.358 \\
\hline Male & 9 & 17 & & \\
\hline Female & 6 & 20 & & \\
\hline Tumor size, $\mathrm{cm}^{3}$ & & & 5.996 & 0.014 \\
\hline$\leq 6.25$ & 12 & 14 & & \\
\hline$>6.25$ & 3 & 23 & & \\
\hline $\mathrm{GH}$ level, $\mathrm{ng} / \mathrm{ml}$ & $36.7 \pm 11.9$ & $17.2 \pm 6.3$ & - & $<0.05$ \\
\hline Resection & & & 4.611 & 0.032 \\
\hline Total & 5 & 26 & & \\
\hline Partial & 10 & 11 & & \\
\hline Recurrence & & & 4.489 & 0.034 \\
\hline Yes & 6 & 5 & & \\
\hline No & 9 & 37 & & \\
\hline SLC20A1 & & & 7.589 & 0.006 \\
\hline High $^{\mathrm{a}}$ & 12 & 14 & & \\
\hline Low & 3 & 23 & & \\
\hline Wif1 & & & 9.369 & 0.002 \\
\hline High & 2 & 24 & & \\
\hline Low & 13 & 13 & & \\
\hline$\beta$-catenin & & & 4.591 & 0.032 \\
\hline High & 11 & 15 & & \\
\hline Low & 4 & 22 & & \\
\hline
\end{tabular}

${ }^{\mathrm{a}} \mathrm{High}$, positive percentage of SLC20A1, Wif1 or $\beta$-catenin is $\geq 50 \%$; low, positive percentage of SLC20A1, Wif1 or $\beta$-catenin $<50 \%$. GH, growth hormone; SLC20A1, solute carrier family 20 member 1; Wif1, Wnt inhibitory factor 1 .

in GH3 cells. The GH levels in the Sh-B and Sh-C groups were $34.7 \pm 10.4$ and $54.6 \pm 14.4 \%$ of that in control GH3 cells, respectively $(\mathrm{P}<0.05$; Fig. $5 \mathrm{~B})$. The transmembrane invasion assay revealed that RNAi-SLC20A1 significantly suppressed cell invasion in the Sh-B and Sh-C groups (Fig. 5C).

RT-qPCR revealed that SLC20A1 silencing reduced the mRNA levels to $0.105 \pm 0.114$ and $0.233 \pm 0.141$-fold for $\mathrm{N}$-cadherin (N-CAD), $0.216 \pm 0.185$ and $0.346 \pm 0.172$-fold for vimentin, $0.294 \pm 0.155$ and $0.387 \pm 0.212$-fold for vascular endothelial growth factor (VEGF), and $0.344 \pm 0.165$ and $0.547 \pm 0.282$-fold for matrix metalloproteinase-2 compared with the control group. There was no significant difference in the expression levels of E-cadherin, matrix metalloproteinase- 9 and Snail. In additional, no significant difference was observed between the control group and scramble group (Fig. 5D). 

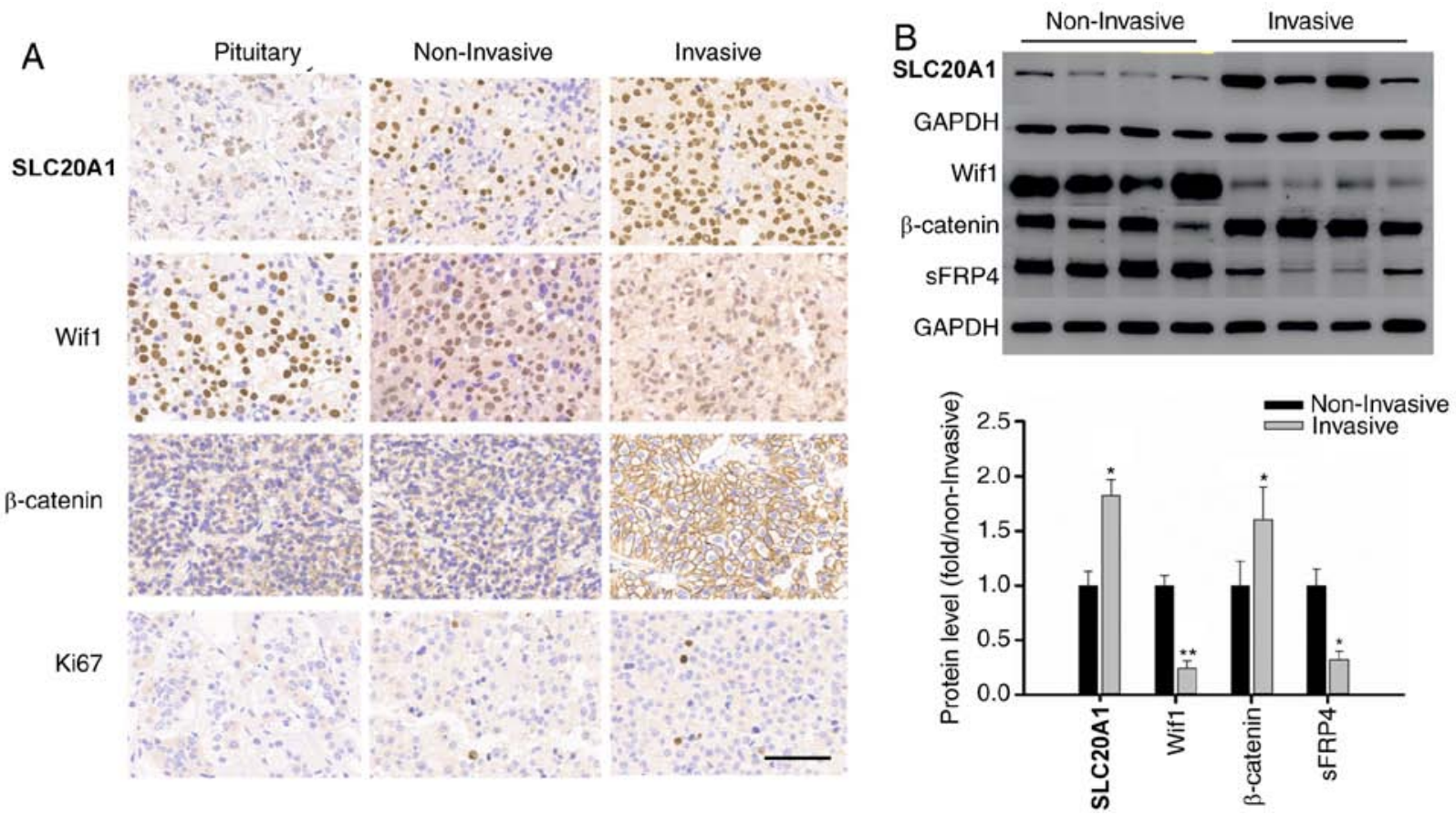

Figure 1. Expression of SLC20A1, Wif1, $\beta$-catenin and Ki67, assessed by tissue microarray in 52 somatotroph adenomas. (A) Immunohistochemistry analysis. Scale bar, $60 \mu \mathrm{m}$. (B) Western blotting showed higher Wif1 and sFRP4 protein levels and lower $\beta$-catenin level in non-invasive adenomas compared with invasive adenomas. ${ }^{*} \mathrm{P}<0.05,{ }^{* *} \mathrm{P}<0.01$ vs. respective non-invasive group. SLC20A1, solute carrier family 20 member 1; Wif1, Wnt inhibitory factor 1 ; sFRP4, secreted frizzled-related protein 4
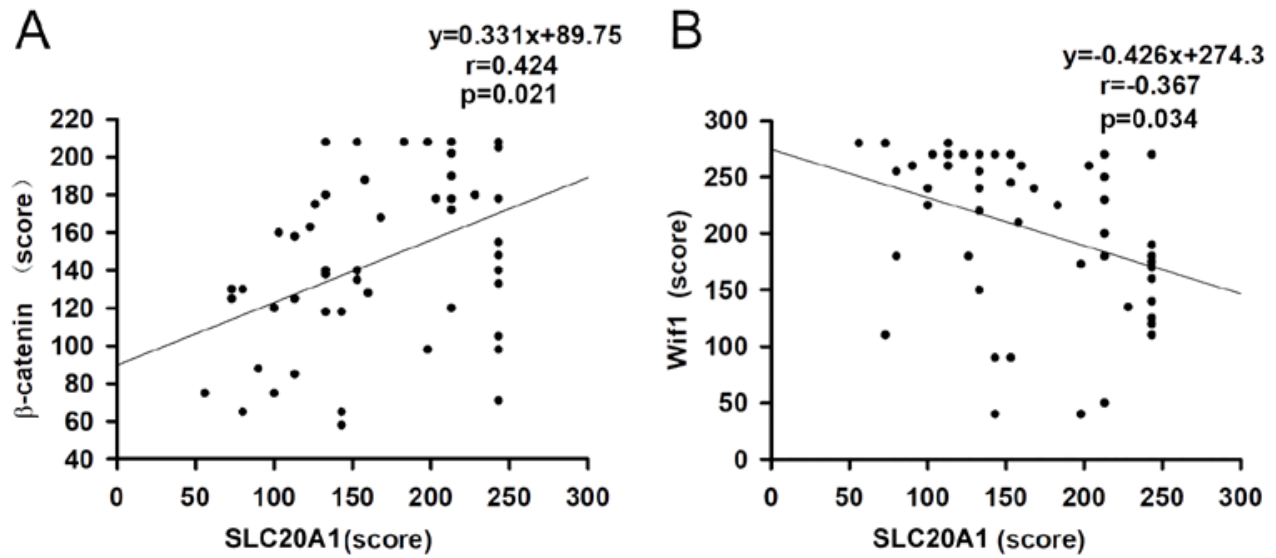

Figure 2. Correlation of SLC20A1, $\beta$-catenin and Wif1. Scatter diagrams demonstrating the correlation between (A) SLC20A1 and $\beta$-catenin and (B) between SLC20A1 and Wif1 following H-score analysis of tissue samples from somatotroph adenomas. SLC20A1, solute carrier family 20 member 1; Wif1, Wnt inhibitory factor 1 .

SLC20A1 silencing inhibits the activation of the Wifl/ $\beta$ catenin signaling pathway. Aberrant expression of the Wifl and $s F R P$ genes has been reported to be associated with the malignant and invasive characteristics of certain human tumors, including somatotroph adenomas (17,18). RT-qPCR revealed that the mRNA levels of Wif1 in the Sh-B and Sh-C groups were $4.3 \pm 1.2$ and $3.6 \pm 0.7$-fold, respectively, of those in the control GH3 cells, while the mRNA levels of sFRP4 were $5.8 \pm 1.3$ and $4.6 \pm 0.9$-fold of those in the control GH3 cells (Fig. 6). Western blotting detected that the Sh-B and Sh-C segments of SLC20A1 could evidently increase the levels of Wif1 and sFRP4, and significant decrease the $\beta$-catenin level in the Sh-B group (Fig. 6).

\section{Discussion}

Somatotroph adenomas are pituitary tumors that secrete GH and IGF-1, resulting in chronic systemic disease with complications and increased mortality when not adequately treated. To date, no novel recurrent mutated genes have been identified in sporadic adenomas except for GNAS $(19,20)$. By allowing the cells to move more quickly out of the $\mathrm{G}_{0} / \mathrm{G}_{1}$ phase of the cell cycle, overexpression of SLC20A1 could confer faster adhesion and migration to the NIH3T3 cell line (10). The present study evaluated the levels of SLC20A1 and the Wnt/ $/$-catenin signaling pathway, and their role in the tumorigenesis and clinical features of 52 somatotroph adenomas. 
A

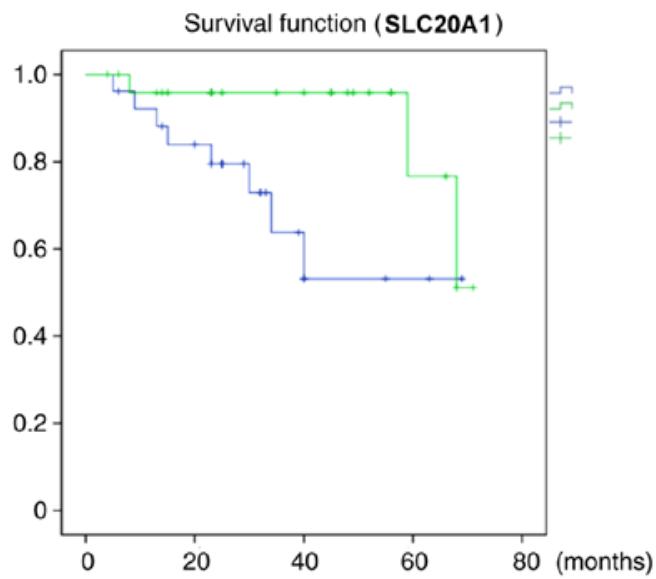

B

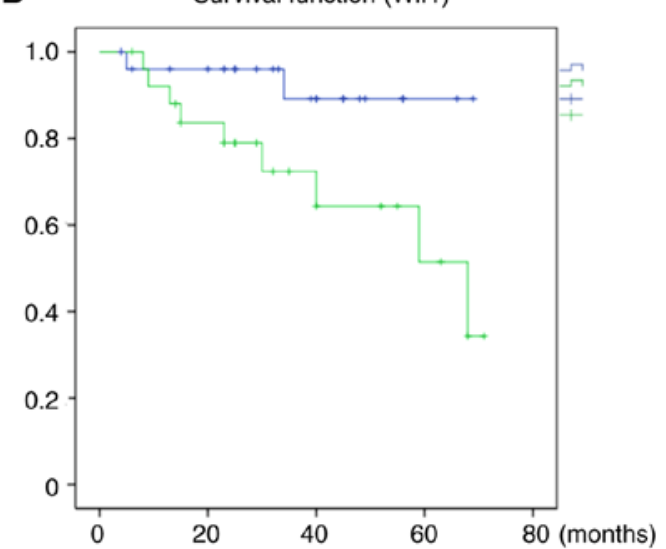

Figure 3. Average PFS in 52 patients with somatotroph adenomas. (A) Average PFS according to SLC20A1 levels. (B) Average PFS according to Wif1 levels. Blue line, high-level group; green line, low-level group. PFS, progression-free survival; SLC20A1, solute carrier family 20 member 1; Wif1, Wnt inhibitory factor 1 .

A

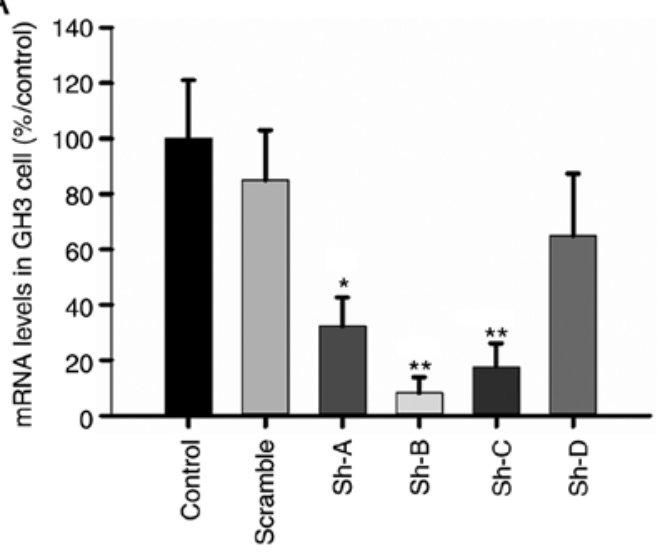

B SLC20A1 GAPDH
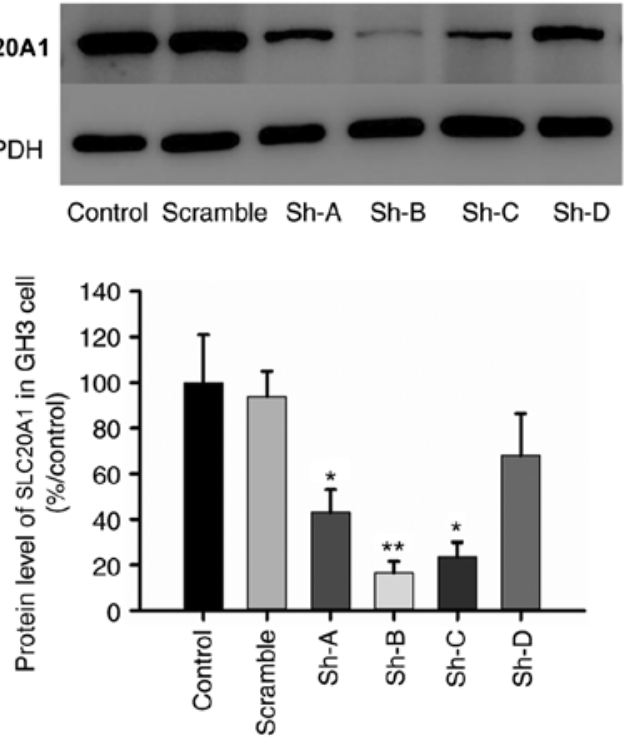

Figure 4. Efficiency of four shRNA segments in GH3 cells. (A) Reverse transcription-quantitative PCR data showing that the mRNA levels of SLC20A1 in the Sh-A-D groups were reduced to $32.3 \pm 10.4,8.2 \pm 5.7,17.7 \pm 8.4$ and $64.9 \pm 22.4 \%$, respectively, of the mRNA levels in control GH3 cells after $72 \mathrm{~h}$ of transfection. (B) Western blot analysis showing that the SLC20A1 level in the Sh-B and Sh-C groups reduced to $16.6 \pm 4.7$ and $23.6 \pm 5.3 \%$, respectively, of the control group. $\mathrm{n}=3 .{ }^{*} \mathrm{P}<0.05,{ }^{* *} \mathrm{P}<0.01$ vs. respective control. sh, short hairpin; SLC20A1, solute carrier family 20 member 1 .

Compared with other subtypes of pituitary adenomas, somatotroph adenomas are associated with higher morbidity and mortality. Main risk factors include histological subtype and tumor invasion as well as the presence of molecular biomarkers, including Ki67, p53 and IGF-1 $(21,22)$. Epidermal growth factor-like domain multiple 7 protein and sparsely granulated adenomas may serve as useful biomarkers of somatotroph adenoma invasion and prognosis (23). However, several predictive biomarkers have failed in clinical research trials of neuroendocrine tumors (24). There is an urgent unmet need to incorporate novel biomarker candidates in order to obtain robust prospective validation. The present IHC results indicated that high expression of SLC20A1 may promote the malignant potential of somatotroph adenomas. High levels of expression of SLC20A1 and low levels of expression of Wif1 were observed in somatotroph adenomas, as well as a longer
PFS in patients with low SLC20A1 and/or high Wif1. There are few cell lines used for the study of pituitary adenomas. The MMQ cell line (25) is used for prolactinomas, the GH3 cell line (26) is used for somatotroph adenomas and the Att20 cell line (27) is used for corticotroph adenomas. GT1-1 cells (28) mainly secrete luteinizing hormone and low levels of GH. In vitro, the $\mathrm{Wnt} / \beta$-catenin signaling pathway may be involved in the cell proliferation, migration and GH secretion of GH3 cells via overexpression of SLC20A1.

SLC20A1 is transcribed in response to the activation of nuclear factor- $\mathrm{\kappa B}(\mathrm{NF}-\mathrm{\kappa B})$ during cancer cell progression (29). Furthermore, SLC20A1 inhibits tumor necrosis factor-induced apoptosis through the main antiapoptotic signals triggered by the mitogen-activated protein kinase-Jun N-terminal kinase signaling pathway $(30,31)$. In fact, $\mathrm{NF}-\kappa \mathrm{B}$ and $\beta$-catenin are constitutively activated by upstream serine/threonine kinases 

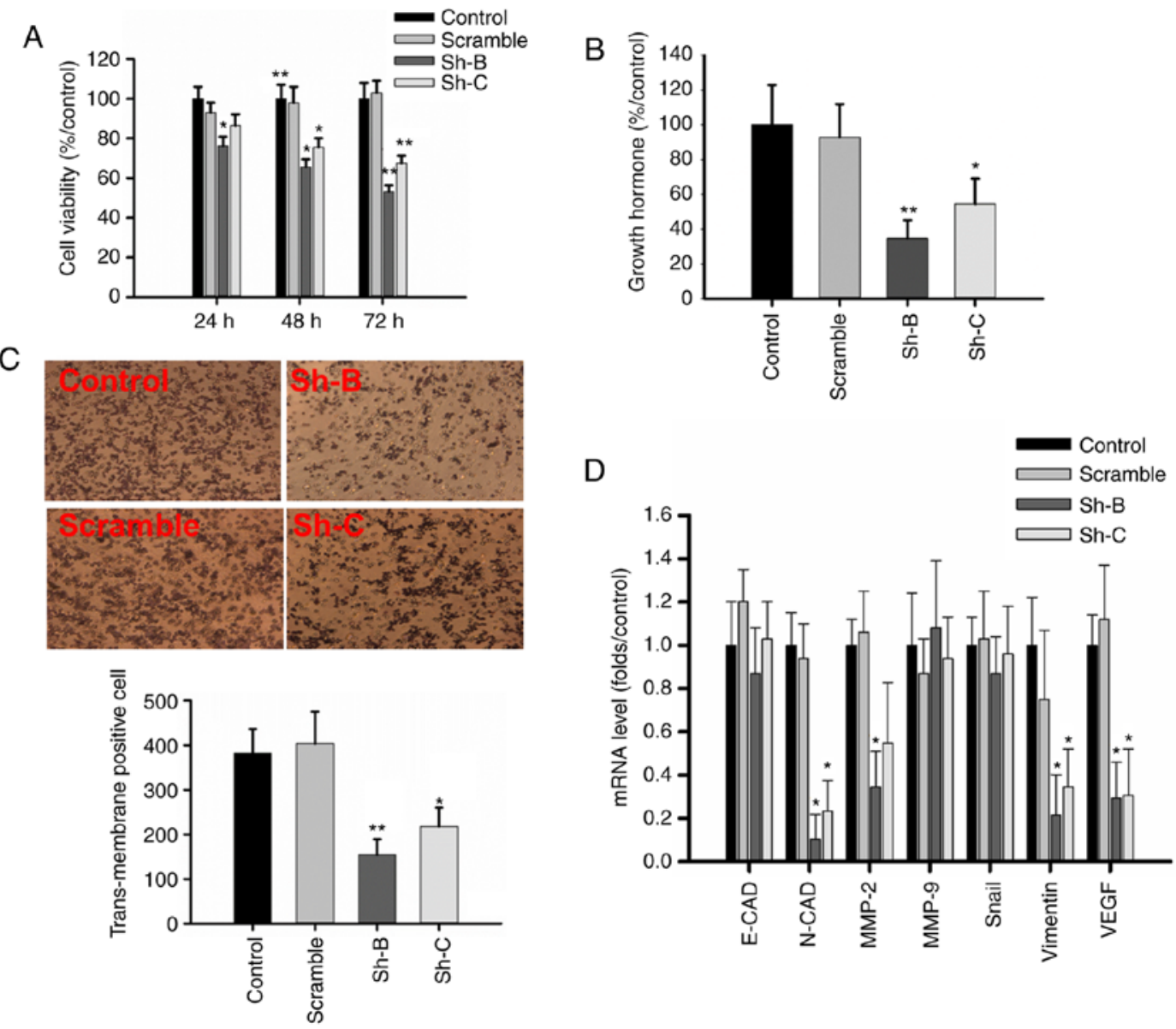

Figure 5. RNAi-SLC20A1 suppresses cell proliferation, GH secretion and migration of GH3 cells. (A) Effect on cell viability, as shown by MTS assay. (B) ELISA revealed that RNAi-SLC20A1 could reduce GH secretion. (C) The effect on invasion, as shown by the transwell experiment. Magnification, $\mathrm{x} 200$. (D) The mRNA level of genes associated with migration and invasion upon RNAi-SLC20A1 in GH3 cells. $\mathrm{n}=3$. ${ }^{*} \mathrm{P}<0.05$, ${ }^{* *} \mathrm{P}<0.01$ vs. respective control. RNAi, RNA interference; SLC20A1, solute carrier family 20 member 1; GH, growth hormone; sh, short hairpin; E-CAD, E-cadherin; N-CAD, N-cadherin; MMP, matrix metalloproteinase; VEGF, vascular endothelial growth factor.

A

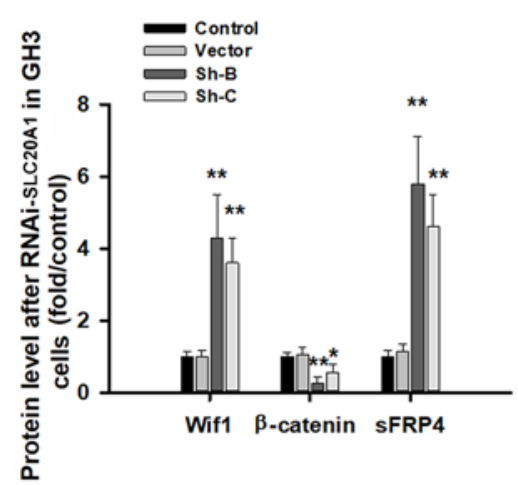

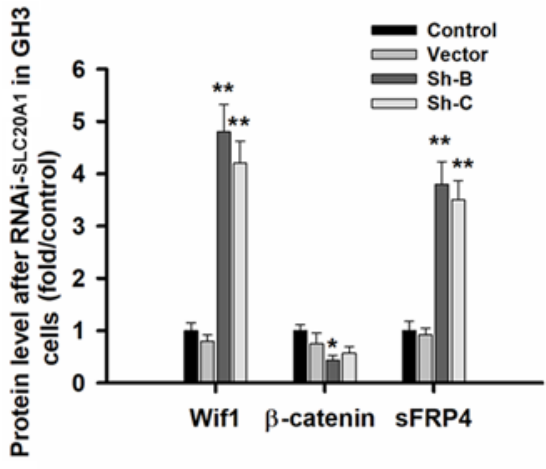

B

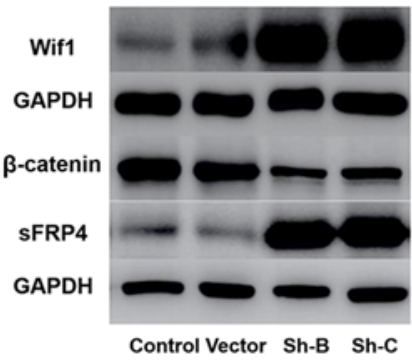

Figure 6. RNAi-PIT inhibits the Wnt/ $\beta$-catenin pathway. (A) Reverse transcription-quantitative PCR analysis revealed significant changes in Wif1, $\beta$-catenin and sFRP4 mRNA levels in GH3 cells. (B) Western blot analysis revealed a significant change in Wif1, $\beta$-catenin and sFRP4 proteins in the Sh-B and Sh-C groups compared with the control group. The protein levels of Wif1 in the Sh-B and Sh-C groups were $4.8 \pm 0.52$ and $4.2 \pm 0.42$-fold greater, respectively, than those in the control GH3 cells, while the protein levels of sFRP4 in the Sh-B and Sh-C groups were 3.8 \pm 0.43 and 3.5 $\pm 0.37-$ fold greater, respectively, than those in the control GH3 cells. $\mathrm{n}=3$. ${ }^{*} \mathrm{P}<0.05,{ }^{* *} \mathrm{P}<0.01$ vs. respective control. RNAi, RNA interference; SLC20A1, solute carrier family 20 member 1 ; Wif1, Wnt inhibitory factor 1 ; sFRP4, secreted frizzled-related protein 4 ; sh, short hairpin.

implicated in malignant transformation, including apoptosis evasion (32). There was a significant positive correlation reported between the $\mathrm{H}$-scores of $\beta$-catenin and c-myc expression and aggressiveness in 212 patients with NFPAs (33). In a previous study, RT-qPCR confirmed the lower mRNA levels of Wif1 and sFRP2/4 in all pituitary adenoma subtypes, including 
somatotroph adenomas, compared with normal pituitary specimens (34). In the present study, SLC20A1 and $\beta$-catenin were increased in the invasive somatotroph adenomas compared with the non-invasive somatotroph adenomas or normal pituitary glands. A positive correlation between SLC20A1 and $\beta$-catenin, and a negative correlation between SLC20A1 and Wif1, was identified by IHC. Follow-up data also revealed the potential of SLC20A1 and Wif1 as predictive factors for somatotroph adenoma recurrence due to high recurrence rate and shorter time to recurrence in patients with high SLC20A1 or low Wif1.

The Wnt/ $\beta$-catenin signaling pathway plays an important role in the adhesion, invasion and metastasis of pituitary tumors, as well as development of these tumors and tumorigenesis (35). The activation of this pathway is an important factor for VEGF production during the process of angiogenesis. Wif1 overexpression plays an important role in the suppression of cell migration, and Wif1 knockdown enhances the migratory potential of glioblastomas through Wnt family member $5 \mathrm{~A}$ activation in vitro and in an orthotopic brain tumor model $(36,37)$. In vitro, silencing of SLC20A1 inhibits the proliferation and migration of GH3 cells. Western blotting revealed that SLC20A1 could reduce the Wif1 and sFRP4 protein levels due to higher Wif1 and sFRP4 in the Sh-B or Sh-C groups compared with the control or scramble groups. Epithelial-mesenchymal transition (EMT) markers such as N-cad, vimentin and Snail are important indicators of the appearance of cystic lesions, tumor progression, bone destruction and endocrine functions in somatotroph adenomas (38). The present data revealed that SLC20A1 evidently regulated the mRNA levels of N-CAD, VEGF and vimentin, which are associated with cell invasion and migration, after $72 \mathrm{~h}$ of RNAi. Taken together, these data suggest a novel mechanism for the role of SLC20A1 in cell proliferation through the Wnt $/ \beta$-catenin signaling pathway in $\mathrm{GH} 3$ cells.

In conclusion, the present study demonstrated that a high SLC20A1 level is positively associated with the tumor size, invasive behavior and tumor recurrence of somatotroph adenomas. Furthermore, SLC20A1 may be associated with activation of the Wnt/ $\beta$-catenin signaling pathway. Furthermore, in vitro experiments demonstrated that silencing SLC20A1 inhibited cell proliferation and invasion through inhibition of genes associated with EMT. However, the present study had certain limitations. Due to the small sample size and possible selection bias in the present study, it is necessary to confirm and validate the conclusions in further studies with larger sample sizes.

\section{Acknowledgements}

Not applicable.

\section{Funding}

The present study was supported by Beijing Natural Science Foundation of China (grant no. 7162035), Beijing High Level Program (grant no. 2015-3-040) and the National Natural Science Foundation of China (grant no. 81601205).

\section{Availability of data and materials}

The datasets used and/or analyzed during the current study are available from the corresponding author on reasonable request.

\section{Authors' contributions}

JL contributed to the writing and the IHC experiment. WD contributed to the IHC experiment. ZL performed the WB experiment and follow up. HW performed the cell culture. HG was involved in the cell function experiments and revising the manuscript. YZ designed the experiment and performed the statistical analysis.

\section{Ethics approval and consent to participate}

The protocols were approved by the Internal Review Board of Beijing Tiantan Hospital affiliated to Capital Medical University and the study was conducted according to the principles of the Declaration of Helsinki (no. KY-2013-02). Informed consent was obtained from all patients.

\section{Patient consent for publication}

Not applicable.

\section{Competing interests}

The authors declare that they have no competing interests.

\section{References}

1. AlDallal S: Acromegaly: A challenging condition to diagnose. Int J Gen Med 11: 337-343, 2018.

2. Inoshita $\mathrm{N}$ and Nishioka H: The $2017 \mathrm{WHO}$ classification of pituitary adenoma: Overview and comments. Brain Tumor Pathol 35: 51-56, 2018.

3. Abreu A, Tovar AP, Castellanos R, Valenzuela A, Giraldo CM, Pinedo AC, Guerrero DP, Barrera CA, Franco HI, RibeiroOliveira A Jr, et al: Challenges in the diagnosis and management of acromegaly: A focus on comorbidities. Pituitary 19: 448-457, 2016.

4. Kempf J, Schmitz A, Meier A, Delfs N, Mueller B, Fandino J, Schuetz $\mathrm{P}$ and Berkmann S: Adenoma size and postoperative IGF-1 levels predict surgical outcomes in acromegaly patients: Results of the Swiss Pituitary Registry (SwissPit). Swiss Med Wkly 148: w14653, 2018.

5. Välimäki N, Demir H, Pitkänen E, Kaasinen E, Karppinen A Kivipelto L, Schalin-Jäntti C, Aaltonen LA and Karhu A: Whole-genome sequencing of growth hormone (GH)-secreting pituitary adenomas. J Clin Endocrinol Metab 100: 3918-3927, 2015.

6. Picard C, Silvy M, Gerard C, Buffat C, Lavaque E, Figarella-Branger D, Dufour H, Gabert J, Beckers A, Brue T, et al: $\mathrm{Gs}$ alpha overexpression and loss of Gs alpha imprinting in human somatotroph adenomas: Association with tumor size and response to pharmacologic treatment. Int J Cancer 121: 1245-1252, 2007

7. Forster IC, Hernando N, Biber J and Murer H: Phosphate transporters of the SLC20 and SLC34 families. Mol Aspects Med 34: 386-395, 2013.

8. Ravera S, Virkki LV, Murer H and Forster IC: Deciphering PiT transport kinetics and substrate specificity using electrophysiology and flux measurements. Am J Physiol Cell Physiol 293: C606-C620, 2007.

9. Byskov K, Jensen N, Kongsfelt IB, Wielsøe M, Pedersen LE, Haldrup C and Pedersen L: Regulation of cell proliferation and cell density by the inorganic phosphate transporter PiT-1. Cell Division 7: 7, 2012.

10. Kongsfelt IB, Byskov K, Pedersen LE and Pedersen L: High levels of the type III inorganic phosphate transporter PiT-1 (SLC20A1) can confer faster cell adhesion. Exp Cell Res 326: 57-67, 2014.

11. Sato K and Akimoto K: Expression levels of KMT2C and SLC20A1 identified by information-theoretical analysis are powerful prognostic biomarkers in ER-positive breast cancer. Clin Breast Cancer 17: e135-e142, 2017. 
12. Clevers $\mathrm{H}$ and Nusse $\mathrm{R}$ : Wnt $/ \beta$-catenin signaling and disease. Cell 149: 1192-1205, 2012.

13. Song W, Qian L, Jing G, Jie F, Xiaosong S, Chunhui L, Yangfang L, Guilin L, Gao H and Yazhuo Z: Aberrant expression of the sFRP and WIF1 genes in invasive non-functioning pituitary adenomas. Mol Cell Endocrinol 474: 168-175, 2018.

14. Ricardo VL, Robert YO, Gunter K and Juan R: WHO classification of tumours of endocrine organ (4th edition). International agency for research on cancere. France, Lyon, pp.19-23, 2018

15. Liu C, Gao H, Cao L, Gui S, Liu Q, Li C, Li D, Gong L and Zhang Y: The role of FSCN1 in migration and invasion of pituitary adenomas. Mol Cell Endocrinol 419: 217-224, 2016.

16. Livak KJ and Schmittgen TD: Analysis of relative gene expression data using real-time quantitative PCR and the 2(-Delta Delta C(T)) method. Methods 25: 402-408, 2001.

17. Pez F, Lopez A, Kim M, Wands JR, Caron de Fromentel C and Merle P: Wnt signaling and hepatocarcinogenesis: Molecular targets for the development of innovative anticancer drugs. J Hepatol 59: 1107-1117, 2013.

18. Ueland T, Olarescu NC, Jørgensen AP, Otterdal K, Aukrust P, Godang K, Lekva T and Bollerslev J: Increased serum and bone matrix levels of the secreted Wnt antagonist DKK-1 in patients with growth hormone deficiency in response to growth hormone treatment. J Clin Endocrinol Metab 100: 736-743, 2015.

19. Hage M, Viengchareun S, Brunet E, Villa C, Pineau D, Bouligand J, Teglas JP, Adam C, Parker F, Lombès M, et al: Genomic alterations and complex subclonal architecture in sporadic GH-secreting pituitary adenomas. J Clin Endocrinol Metab 103: 1929-1939, 2018.

20. Caimari F and Korbonits M: Novel genetic causes of pituitary adenomas. Clin Cancer Res 22: 5030-5042, 2016.

21. Mete O and Lopes MB: Overview of the 2017 WHO Classification of pituitary tumors. Endocr Pathol 28: 228-243, 2017.

22. Park HH, Kim EH, Ku CR, Lee EJ and Kim SH: Outcomes of aggressive surgical resection in growth hormone-secreting pituitary adenomas with cavernous sinus invasion. World Neurosurg 117: e280-e289, 2018.

23. Wang J, Liu Q, Gao H, Wan D, Li C, Li Z and Zhang Y: EGFL7 participates in regulating biological behavior of growth hormone-secreting pituitary adenomas via Notch2/DLL3 signaling pathway. Tumour Biol 39: 1010428317706203, 2017.

24. Barriuso J, Custodio A, Afonso R, Alonso V, Astudillo A, Capdevila J, García-Carbonero R, Grande E, Jimenez-Fonseca P, Marazuela M, et al: Prognostic and predictive biomarkers for somatostatin analogs, peptide receptor radionuclide therapy and serotonin pathway targets in neuroendocrine tumours. Cancer Treat Rev 70: 209-222, 2018.

25. Su Z, Cai L, Lu J, Li C, Gui S, Liu C, Wang C, Li Q, Zhuge Q and Zhang Y: Global expression profile of tumor stem-like cells isolated from MMQ rat prolactinoma cell. Cancer Cell Int 17: 15, 2017.

26. Occhi G, Losa M, Albiger N, Trivellin G, Regazzo D, Scanarini M, Monteserin-Garcia JL, Fröhlich B, Ferasin S, Terreni MR, et al: The glucose-dependent insulinotropic polypeptide receptor is overexpressed amongst GNAS1 mutation-negative somatotropinomas and drives growth hormone $(\mathrm{GH})$-promoter activity in GH3 cells. J Neuroendocrin 23: 641-649, 2011.
27. Bergeron F, Sirois F and Mbikay M: ACTH secretion by mouse corticotroph AtT 20 cells is negatively modulated by the intracellular level of 7B2. FEBS Lett 512: 259-262, 2002.

28. Peng H, Fan J, Wu J, Lang J, Wang J, Liu H, Zhao S and Liao J Silencing of HEPN1 is responsible for the aggressive biological behavior of pituitary somatotroph adenomas. Cell Physiol Biochem 31: 379-388, 2013.

29. Karin M: Nuclear factor-kappaB in cancer development and progression. Nature 441: 431-436, 2006

30. Salaün C, Leroy C, Rousseau A, Boitez V, Beck L and Friedlander G: Identification of a novel transport-independent function of PiT-1/SLC20A1 in the regulation of TNF-induced apoptosis. J Biol Chem 285: 34408-34418, 2010.

31. Wajant H, Pfizenmaier K and Scheurich P: Tumor necrosis factor signaling. Cell Death Differ 10: 45-65, 2003.

32. Kavitha K, Kowshik J, Kishore TK, Baba AB and Nagini S: Astaxanthin inhibits NF- $\kappa B$ and $W n t / \beta$-catenin signaling pathways via inactivation of Erk/MAPK and PI3K/Akt to induce intrinsic apoptosis in a hamster model of oral cancer. Biochim Biophys Acta 1830: 4433-4444, 2013.

33. Liu C, Wu Y, Yu S, Bai J, Li C, Wu D and Zhang Y: Increased $\beta$-catenin and c-myc expression predict aggressive growth of non-functioning pituitary adenomas: An assessment using a tissue microarray-based approach. Mol Med Rep 5: 1793-1799, 2017.

34. Elston MS, Gill AJ, Conaglen JV, Clarkson A, Shaw JM, Law AJ, Cook RJ, Little NS, Clifton-Bligh RJ, Robinson BG and McDonald KL: Wnt pathway inhibitors are strongly down-regulated in pituitary tumors. Endocrinology 149: 1235-1242, 2008

35. Chambers TJ, Giles A, Brabant G and Davis JR: Wnt signalling in pituitary development and tumorigenesis. Endocr Relat Cancer 20: R101-R111, 2013.

36. Vassallo I, Zinn P, Lai M, Rajakannu P, Hamou MF and Hegi ME: WIF1 re-expression in glioblastoma inhibits migration through attenuation of non-canonical WNT signaling by downregulating the lncRNA MALAT1. Oncogene 35: 12-21, 2016.

37. Wang Y, Sang A, Zhu M, Zhang G, Guan H, Ji M and Chen H: Tissue factor induces VEGF expression via activation of the $\mathrm{Wnt} / \beta$-catenin signaling pathway in ARPE-19 cells. Mol Vis 22: 886-897, 2016

38. Shan XS, Liu Q, Li ZY, Li CZ, Gao H and Zhang YZ: Epithelial-mesenchymal transition induced by SMAD4 activation in invasive growth hormone-secreting adenomas. Open Chem 16: 571-582, 2018. 